
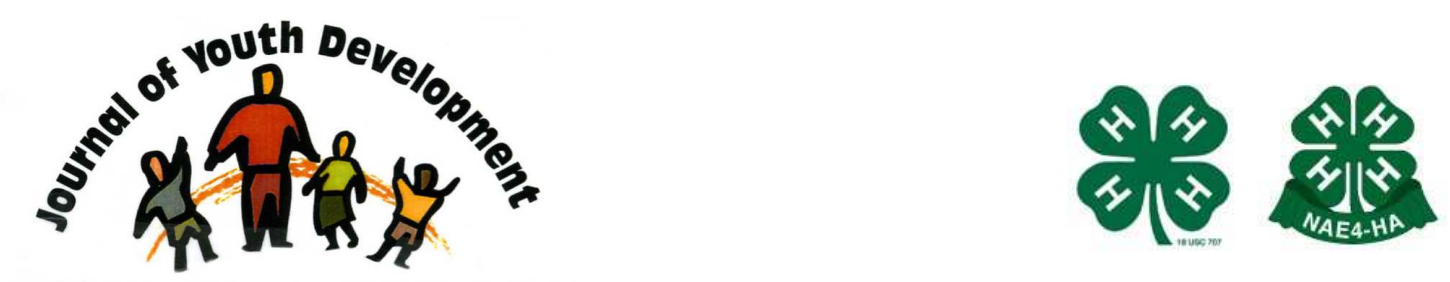

Bridging Research \& Practice

\title{
Urban After-School Partnership Teaches Cooking and My Plate Nutrition
}

\author{
Michelle F. Brill \\ Family and Community Health Sciences \\ Rutgers \\ The State University of New Jersey \\ brill@aesop.rutgers.edu \\ Fred Shaykis \\ Princeton University
}




\title{
JOURNAL OF YOUTH DEVELOPMENT \\ bridging research and practice

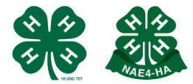

Volume 10, Number 1, Spring 2015

Article 151001FA004

\section{Urban After-School Partnership Teaches Cooking and My Plate Nutrition}

\author{
Michelle F. Brill \\ Rutgers, the State University of New Jersey \\ Fred Shaykis \\ Princeton University
}

\begin{abstract}
Seventeen percent of children in the U.S. are clinically obese and many more are overweight and at risk for obesity. The consequences of childhood overweight and obesity warrant greater efforts in early prevention. A key factor associated with energy intake and weight gain is consumption of foods away from home. Programs to promote eating more home-prepared foods present an encouraging area of intervention for improving children's diet quality and diminishing childhood obesity. This study reports on an urban after-school cooking program implemented through a partnership between Rutgers Cooperative Extension and the Boys and Girls Club. Post-test measures and qualitative observations found that the program increased cooking skills and enjoyment, interest in healthy eating and exposure to healthy foods, and provided knowledge and tools to help modify students' eating habits away from school. Partnerships between after-school providers and Cooperative Extension can provide effective programming in areas with widespread poverty and limited resources.
\end{abstract}

\section{Introduction}

The United States of America is in the midst of an obesity epidemic. Recent data indicate that a full $35 \%$ of American adults and $17 \%$ of children are clinically obese, with many more overweight and at-risk for obesity (Ogden, Carroll, Kit, \& Flegall, 2014). These rates represent a dramatic increase since the 1970 's, when only $15 \%$ of adults and $5 \%$ of children were obese (Flegall, Carroll, Ogden, \& Curtin, 2010). While the causes of overweight and obesity are complex and manifold, dietary intake patterns play a crucial role in the pathogenesis of obesity, type-2 diabetes, and other common causes of disability and death (CDC, 2014). 
The situation in New Jersey's capital city of Trenton is especially dire. Trenton is a racially and ethnically diverse city of 84,913 residents (52\% African American; 34\% Hispanic or Latinos of any race) with a significant proportion (26.6\%) living below or near the poverty line, compared to $14.9 \%$ nationally. The median household income is $\$ 36,662$, compared to $\$ 53,046$ nationally (U.S. Census Bureau, 2014). African-Americans, Latinos, and low-income individuals are all at a higher risk of becoming overweight or obese compared to the general population (CDC, 2014; Drewnowshi, \& Specter, 2004). Thus, it should come as no surprise that Trenton, given its demographics, has alarmingly high rates of obesity and other nutrition-related diseases. Of the five cities examined in the New Jersey Childhood Obesity Study, Trenton ranked highest in childhood obesity and overweight with $28 \%$ of children ages 3-19 obese and $47 \%$ overweight or obese (Rutgers Center for State Health Policy, 2010).

Targeting children, especially young children, for obesity prevention and treatment efforts is a critical strategy for a number of reasons. First, the finding that the older an overweight child is, the more likely the weight problems are to carry over into adulthood highlights the importance of early interventions (Guo, \& Chumlea, 1999). Second, overweight children, regardless of their adult weight status, are at a higher risk of developing nutrition-related health conditions later in life, including cardiovascular disease, type 2 diabetes, stroke, and skeletal disorders (Beilin, \& Huang, 2008; Daniels, 2006 ). Third, obese and overweight children suffer adverse social, psychological, and academic consequences as a result of their weight, are more likely to be bullied by their peers and are less likely to do well in school (Gurley-Calvez, \& Hibbinbotham, 2010; Janssen, Craig, Boyce, \& Pickett, 2004). Clearly, the consequences of childhood overweight and obesity warrant making greater efforts in prevention and treatment from an early age. Furthermore, school-age children are a key population for promoting positive nutritional habits because children are still forming nutrition-related attitudes and behaviors, and schools offer a venue for widespread dissemination of information (U.S. Department of Health and Human Services, 2010).

\section{Promising Interventions}

In considering target behaviors for intervention, research has shown that one of the key factors associated with energy intake and weight gain is the consumption of foods away from home (USDA Economic Research Service, 2013). Processed and restaurant-prepared foods tend to be lower in nutrients and higher in calories, saturated fats, and added sugar. Eating more homeprepared meals, as opposed to foods eaten away from home (FAFH), is associated with lower energy consumption, improved nutritional intake, and healthier body weight (Binkley, 2008; Taveras, et al., 2005; USDA ERS, 2010). Consumption of FAFH has risen dramatically in recent decades as daily food preparation at home has decreased (Smith, Ng, \& Popkin, 2013). In 2012, Americans spent 43\% of their food budget on FAFH, as compared to $26 \%$ in 1970 . Furthermore, between 1977-78 and 2005-08, U.S. consumption of FAFH increased from $18 \%$ to $32 \%$ of total calories eaten (USDA Economic Research Service, 2013).

These data suggest that policies and programs to promote eating more home-prepared meals and snacks present an encouraging area of intervention for improving children's diet quality and diminishing childhood obesity. A recent review found that the main obstacles to preparing more food at home include lack of food preparation knowledge and skills (Soliah, Walter, \& Jones, 2012). Thus, equipping individuals and families with the knowledge and skills they need to cook more at home is a promising strategy for reducing energy over-consumption, improving the nutritional quality of foods consumed, and reducing overweight and obesity and other dietrelated disorders. 
A program that teaches both nutritional knowledge and cooking skills to children has the potential to reduce barriers to healthy food preparation and help young individuals get on track toward developing healthy lifestyles. Teaching cooking skills to children can benefit families as well. Evaluations of past cooking programs for children have revealed that after participating, children are more likely to try new foods, ask their parents to buy new foods, and to be actively involved in food preparation at home (Lukas, \& Cunningham-Sabo, 2011). Additionally, handson and multifaceted approaches to teaching nutrition, qualities inherent in a cooking class, are more successful in effecting changes in attitude and behavior than traditional nutrition education taught in a lecture or class discussion format (Contento, 2007). Cooking classes also provide an opportunity to develop social skills and to model socially appropriate mealtime behavior (e.g. Lukas \& Cunningham-Sabo, 2011).

Schools and after-school programs can provide excellent opportunities for efficient and widespread promotion of positive nutritional behaviors (CDC, 2011). Yet many schools have reduced class time devoted to health and physical education, and family and consumer sciences, due to the current high pressure "teaching to the test" educational climate. Cooking and food preparation instruction have been given lower priority, though there is growing awareness and momentum building to return "home economics" to the curriculum (Duyff, 2010). Considering the current climate of limited in-school time and resources set aside for family and consumer sciences during the school day, after-school programming is an especially promising venue for teaching the knowledge and skills that can help children lead healthier lifestyles and maintain healthy weights.

\section{Reports of Earlier Programs}

Several programs to teach cooking and nutrition to children have been implemented in the past. A cooking class program carried out and evaluated by Oklahoma Cooperative Extension led to a significant increase in fruit and vegetable consumption for both children and adults, with children showing greater increases in intake (Brown, \& Hermann, 2005). The same program also led to improvements in food safety behaviors of its participants. However, this program was not specific to children and was not carried out in schools.

Another program, "The Adventure Bites - Cooking with Kids" (Brandt, \& Murray, 2013), partnered with local schools and the YMCA in Washington State to offer cooking and nutrition education classes to students in an after-school setting. Evaluation of the program showed evidence of moderate improvements in cooking knowledge and healthy eating behaviors. While the data from this program are incomplete and lack consistency across program sites, they do provide some evidence that partnering with local after-school providers can be a viable method of offering nutrition and cooking classes. The "Adventure Bites" program used a train the trainer model, in which the curriculum developers provided an experiential training workshop to teach YMCA staff how to administer the lessons to children.

\section{Purpose of this Paper}

This study reports on an after-school cooking program conducted in Trenton, New Jersey through a partnership between Rutgers Cooperative Extension of Mercer County's departments of 4-H Youth Development and Family and Community Health Sciences (FCHS), and the Boys and Girls Club of Greater Mercer County. The program was funded by a $21^{\text {st }}$ Century Community Learning Center grant from the New Jersey and U.S. Departments of Education. This study was approved by the Institutional Review Board of Rutgers University. 
The program is grounded in the health belief model, which argues that when people decide to engage or not engage in a health behavior (choosing to cook or eat healthy), a number of factors impact their decision, including the perceived severity of the health problem, their perceived susceptibility to the problem, the perceived benefits of engaging in the particular health behavior, perceived barriers to engaging in that health behavior, their perceived ability to perform the health behavior (self-efficacy), and cues to action (Redding, Rossi, Rossi, Velicer, \& Prochaska, 2000). According to this theory, modifying any one of these factors for an individual will affect their likelihood of performing a particular health behavior.

This program targeted those facets of the health belief model believed to be most applicable to children. Lessons were designed to promote the advantages of cooking and eating healthy (increasing perceived benefits) and to increase cooking and healthy food choice skills (decreasing perceived barriers and increasing self-efficacy). The goal of the cooking series was to combine nutrition education with hands-on food preparation in order to improve both knowledge and skills relating to healthy eating, a strategy more likely to affect eating behaviors than addressing either knowledge or skills alone.

\section{After-School Cooking Program Objectives}

The specific objectives of the cooking classes were:

- To provide opportunities to cook healthy and appealing recipes

- To introduce participants to new foods, food preparation techniques, and the basics of food safety

- To increase participants' healthy eating habits at home and away from home

- To increase participants' knowledge of the MyPlate guidelines

- To develop participants' social skills and manners in a setting that modeled family style or social dining

- To ignite an interest in cooking that could carry over to the child's home and family

The effectiveness of the program was evaluated using pre and post survey data collected from participants.

\section{Program Description}

The Rutgers Cooperative Extension of Mercer County 4-H Youth Development department has a pre-existing partnership with several after-school sites in Trenton through the Boys and Girls Club of Greater Mercer County. Three sites were selected in which to provide a weekly nutrition education/cooking series utilizing the expertise of the FCHS Extension agent. The three program sites were (1) Jefferson Elementary School, (2) Boys and Girls Club Headquarters, and (3) P.J. Hill Elementary School. Each program site provided basic facilities for the lessons, an assistant and administrative support. The FCHS Extension Agent was responsible for selecting the recipes based on nutritional profile, ease of preparation, cost and student preference, and bringing the ingredients, cookware, and other educational materials to the program sites. Average weekly cost for food and incidentals was $\$ 25.00$ or $\$ 2.00$ per student.

\section{Enrollment and program site characteristics}

The enrollment, recruitment method, length of program, and resources provided varied by site (Table 1). At two sites, students were assigned to take the cooking class by the site coordinator, and at one site, students were given the choice to participate in the cooking class as an elective activity. Teaching space, kitchen access and available appliances varied by program site, and the FCHS Extension Agent brought small appliances and utensils as needed for each recipe such as an electric hot plate, cookware and blender. Where kitchen access was 
available, only the sink was used for washing produce and general cleanup. The Agent was not allowed use of the stove, oven, microwave, or refrigerator.

Table 1

Program Site Descriptions

\begin{tabular}{|l|l|l|l|l|l|}
\hline Program Site & $\begin{array}{l}\text { Number of } \\
\text { Students } \\
\text { Enrolled }\end{array}$ & $\begin{array}{l}\text { Recruitment } \\
\text { Method }\end{array}$ & $\begin{array}{l}\text { Grades } \\
\text { Enrolled }\end{array}$ & $\begin{array}{l}\text { Number } \\
\text { of } \\
\text { Sessions }\end{array}$ & Space Provided \\
\hline $\begin{array}{l}\text { Jefferson } \\
\text { Elementary } \\
\text { School }\end{array}$ & 32 & Assigned & $4-8^{*}$ & 19 & $\begin{array}{l}\text { Half of multi- } \\
\text { purpose room }\end{array}$ \\
\hline $\begin{array}{l}\text { Boys \& Girls } \\
\text { Club } \\
\text { Headquarters }\end{array}$ & 21 & Assigned & $5-7$ & 11 & Classroom \\
\hline $\begin{array}{l}\text { P.J. Hill } \\
\text { Elementary } \\
\text { School }\end{array}$ & 14 & Elective & $4-5$ & 9 & School cafeteria \\
\hline
\end{tabular}

* Students were divided into two groups - grades 4-5 and 6-8

\section{Lesson Content and Style}

Prior to the first cooking session all students were taught proper hand washing and safe food handling. Food allergy information was collected to ensure that no allergens would be introduced into the environment. After the introductory lesson on food safety and hygiene, all subsequent lessons centered on the preparation of a healthful new recipe. Some recipes were "no-cook" such as fruit smoothies and yogurt banana splits, while others utilized an electric skillet to cook foods such as quesadillas, French toast or turkey tacos. Students took turns stepping up to follow each step in the recipe directions and to set the table and clean up. Nutrition education was based on the key consumer messages from the Dietary Guidelines for Americans 2010 and MyPlate. All classes used an informal teaching style and included ageappropriate food preparation skills. All sessions modeled family-style or social eating settings and included group discussions about food and nutrition topics.

Table 2

Topics Covered

\begin{tabular}{|l|l|}
\hline Food Preparation and Social Skills & Nutritional Messages \\
\hline $\begin{array}{l}\text { Hand-washing; kitchen and food safety } \\
\text { procedures }\end{array}$ & Clean, separate, chill, cook \\
\hline $\begin{array}{l}\text { Following a recipe; measurement; sequencing; } \\
\text { culinary vocabulary }\end{array}$ & $\begin{array}{l}\text { Appropriate portion sizes; Matching weekly } \\
\text { recipe ingredients with the MyPlate food } \\
\text { groups }\end{array}$ \\
\hline $\begin{array}{l}\text { Using age-appropriate food preparation tools } \\
\text { and techniques (e.g. stir-frying; blending; } \\
\text { grating, peeling) }\end{array}$ & $\begin{array}{l}\text { Food preferences and healthy recipe } \\
\text { substitutions }\end{array}$ \\
\hline Setting the table and cleaning up & $\begin{array}{l}\text { Smart shopping tips; participation in family } \\
\text { chores }\end{array}$ \\
\hline Meal-time social skills & Conversation starters; character education \\
\hline
\end{tabular}


Each session provided an opportunity to reinforce previously learned skills and information, as well as to introduce new topics. At each session, participants were given copies of the recipe to take home, and were encouraged to make it with their families. At the conclusion of the series, each participant was presented with a cookbook containing the recipes used throughout the course. Cookbooks were illustrated by the students and included photos of the students taken throughout the program.

\section{Program Evaluation}

\section{Participant Demographics}

Of the 32 students who listed their race on the pre and/or post-tests, 19 (56\%) self-identified as non-Hispanic Black only, $7(21 \%)$ as Hispanic only, and $8(24 \%)$ as multiracial or other races. Of those who identified their gender, 24 (65\%) were boys, and 13 (35\%) were girls.

\section{Pilot survey and resulting modifications}

The pilot study was carried out at Jefferson Elementary School in 2012. A post-test survey was pilot tested at the conclusion of the program. Eighty percent (80\%) of respondents reported that since attending this program, they enjoy cooking more and that cooking is more important to them. Seventy one percent $(71 \%)$ of respondents reported that eating healthy is more important to them, and about half of students surveyed reported being more willing to try new foods. Sixty percent $(60 \%)$ of respondents reported that they help prepare more meals at home; and $60 \%$ reported that following a recipe was easier.

The pilot survey included dietary recall questions comparing consumption frequency of fruits, vegetables, breakfast and sugar sweetened beverages before and after the cooking club. These data were unreliable because the students were unable to recall consumption patterns from approximately 5 months prior to the post test and thus are not reported here.

The survey also included questions testing knowledge of the MyPlate guidelines. However, the results are not reported as the investigators believe that these questions may not be valid measures of knowledge change due to the inconsistent use of MyPlate teaching tools throughout the series. Both the survey and use of MyPlate teaching tools were subsequently revised for content and clarity in order to improve their validity and reliability. For example, numerous questions on the survey that tested knowledge of MyPlate guidelines were rephrased to more directly and clearly reflect key messages. The two later program sites also received more consistent exposure to MyPlate teaching tools throughout the lessons. Two of the True/False questions from the pilot survey were retained: "Half of my plate should contain fruits and vegetables" and "Chicken, meat, fish, beans and eggs belong to the protein group." Seventy one percent (71\%) and $73 \%$, respectively, of students answered these questions correctly on the pilot survey at Jefferson Elementary, as compared to $87 \%$ and $83 \%$ on the post-surveys administered at the later program sites (see Table 4). These differences in postsurvey results provide evidence that the more targeted teaching of MyPlate messages led to improvements in participant knowledge of MyPlate key messages.

\section{Pre-test survey results}

Based on the results of the pilot survey, a pre-test was added and the post test was redesigned and administered at the other two locations, Boys \& Girls Club and P.J. Hill Elementary School. Since the same curriculum was taught and the same survey instrument used in both program sites, data from the two sites were combined for analysis. Pre-test results are displayed in Table 3. 
Table 3

Pre-test Survey Results $\left(\mathrm{n}=22^{*}\right)$

\begin{tabular}{|l|l|}
\hline Behavior and skill self-assessment questions (yes or no) & \% Responding "Yes" \\
\hline I help prepare meals at home & 64 \\
\hline Learning to cook is important to me & 100 \\
\hline I enjoy cooking & 95 \\
\hline I am willing to try new foods & 95 \\
\hline I can follow a recipe & 91 \\
\hline Eating healthy is important to me & 76 \\
\hline Knowledge of MyPlate Messages (true or false) & \% Responding Correctly \\
\hline Half of my plate should contain fruits and vegetables & 86 \\
\hline White bread and whole wheat bread are both whole grains & 59 \\
\hline Chicken, meat, fish, beans and eggs belong to the protein group & 82 \\
\hline $\begin{array}{l}\text { At my age, dairy foods like milk, yogurt and cheese should be } \\
\text { low-fat or fat free }\end{array}$ & 100 \\
\hline $\begin{array}{l}\text { Different color fruits and vegetables have different vitamins and } \\
\text { minerals }\end{array}$ & 82 \\
\hline
\end{tabular}

\section{Post-test survey results}

The post-test survey was administered at the completion of the series in order to assess changes in skills or behaviors since the program had begun. Post-test results are displayed in Table 4.

Table 4

Post-test Survey Results ( $n=23 *$ )

\begin{tabular}{|l|l|}
\hline Behavior and skill self-assessment questions (yes or no) & \% Responding "Yes" \\
\hline Since attending cooking class, I help prepare more meals at home & 65 \\
\hline Since attending cooking class, learning to cook is more important to me & 96 \\
\hline Since attending cooking class, I enjoy cooking more & 91 \\
\hline Since attending cooking class, I am more willing to try new foods & 86 \\
\hline Since attending cooking class, I can follow a recipe more easily & 91 \\
\hline Since attending cooking class, eating healthy is more important to me & 91 \\
\hline Knowledge of MyPlate Messages (true or false) & \% Answering \\
& Correctly \\
\hline Half of my plate should contain fruits and vegetables & 87 \\
\hline White bread and whole wheat bread are both whole grains & 57 \\
\hline Chicken, meat, fish, beans and eggs belong to the protein group & 83 \\
\hline $\begin{array}{l}\text { At my age, dairy foods like milk, yogurt and cheese should be low-fat or } \\
\text { fat free }\end{array}$ & 96 \\
\hline Different color fruits and vegetables have different vitamins and minerals & 82 \\
\hline
\end{tabular}

$* 66 \%$ response rate due to wide variability in weekly attendance 


\section{Discussion}

The pre-test data indicate that at baseline, the vast majority of participants reported that they helped prepare meals at home, enjoyed cooking, were able to follow a recipe, were willing to try new foods, and valued eating healthy and learning how to cook. The post-test data reveal that the majority of participants reported positive changes in their cooking behaviors, skills, and attitudes since the beginning of the cooking series. Ninety six percent (96\%) reported that learning to cook is more important to them and $91 \%$ reported that they enjoyed cooking more, could follow a recipe more easily, and considered eating healthy more important. Eighty six percent (86\%) reported that they were more willing to try new foods and $65 \%$ reported that they helped prepare more meals at home since the cooking series had begun.

No significant changes in knowledge of any of the MyPlate messages were found between the pre and post-tests ( $p>.05$, two-sided t-test). However, results from the pre-test suggest that participants already had sound knowledge of the MyPlate messages, with at least 18 out of 22 $(82 \%)$ participants answering factual questions correctly on four of the five questions. The question that participants most often answered incorrectly asked whether or not "white bread and whole wheat bread are both whole grains." Slightly more than half of the respondents answered this question correctly both before and after the series. It is possible that the structure of the question may account for the lower percentage of students answering correctly, as compared to other MyPlate survey questions. The correct answer to all of the other MyPlate questions was "true" while the correct answer to this question was "false." Students may have been more likely to answer "true" because the correct answer to all other true/false questions was "true."

We suspected that a difference in program recruitment methods and other dissimilarities between program populations could have led to differing survey results. Data were compared to look for pre-test differences between the Boys and Girls Club and P.J. Hill Elementary School. Significant differences were found in two instances. First, 9/9 (100\%) of students who elected to take the cooking class (students at P.J. Hill) reported that healthy eating was important to them while $7 / 12(58 \%)$ of students who were assigned to take the cooking class (students at the Boys and Girls Club) reported that healthy eating was important to them. This difference was significant $(p<.05)$. Second, Boys \& Girls Club participants scored better on the pre-test question about protein with $13 / 13(100 \%)$ answering the question correctly, compared to 5/9 $(56 \%)$ at P.J. Hill $(p<.01)$. Students at the Boys \& Girls Club also performed significantly $(p<$ $.05)$ better on the protein-related question on the post-test.

It is possible that this difference reflects some underlying variation between the after-school program populations at P.J. Hill and Boys \& Girls Club, since P.J. Hill participants attended a Trenton public school and Boys \& Girls Club participants were drawn from various Trenton charter schools. While differences in educational outcomes between charter and traditional public schools is an ongoing and contentious debate in the field of education, the after-school program populations may have had underlying differences in reading comprehension, testtaking ability, or other factors that could have affected performance on the surveys (Betts and Tang, 2011). Another possible explanation is the age difference in the participants at the two program sites. P.J. Hill participants were in grades 4 and 5, while Boys and Girls Club participants were in grades 5-7. This may have affected survey performance, as reading comprehension and test-taking ability tends to increase with higher age and grade level. 


\section{Limitations}

A potential limitation of the survey evaluation tools was that they consisted of exclusively dichotomous questions, with students choosing yes/no or true/false for all questions. The rationale for using this type of question was that questions with more complex structures can be difficult for children of the age group with whom we were working. Furthermore, the Mercer County 4-H program evaluation uses yes/no survey questions for this age group, a precedent that was followed for this study. In spite of the use of dichotomous questions in 4-H program evaluation, we suspect that the reliance on 2-choice questions may limit the validity of the survey results.

The use of dichotomous choice questions for the behavior and skill self-assessment questions also prevents any quantification of the degree of behavior or skill change that participants can self-report. Within this survey design, a participant who is truly passionate about eating healthy and one who is mildly interested in the idea of eating healthy would have the same answer "Yes" - to the question about the importance of eating healthy. Having only yes/no answer choices obscures the degree of endorsement of the behavior, attitude, or skill that each question asks about; it also limits the ability to measure change in an outcome over time (Cates, Blitstein, Hersey, et al., 2014). Future program evaluations could be improved by using a wider variety of question types, and by using continuous measures such as multi-pointed Likert response scales, rather than dichotomous measures.

A difficulty encountered in the cooking series was the large grade span in two of three program sites. A wide age range makes it more challenging to deliver a program that is interesting and relevant to all participants. Furthermore, as mentioned earlier, a large age variation can affect the validity and variability of survey measures. To increase program effectiveness and quality of evaluation, future programs should attempt to target more defined age groups if possible, with lesson content and survey tools tailored to the specific age group.

\section{Conclusions and Implications}

Based on self-report post-test measures and qualitative observations, the cooking series offered at three after-school program sites in Trenton, NJ led to increased cooking skills, greater enjoyment of cooking, and an increased interest in healthy eating for participants. It also increased their exposure to healthy foods and recipes and provided them with useful knowledge and tools to help modify their and their families' eating habits away from school. Fundamentally, this study demonstrates that by creating partnerships between existing afterschool providers and Cooperative Extension Agents, it is possible to offer an engaging, handson, and educational nutrition and cooking series, even in areas with widespread poverty and limited resources for after-school programming.

This study also highlights the need for improved evaluation tools and methods of nutrition education programs. Our results demonstrate that reliance on dichotomous survey questions is not the most valid or useful method for analyzing a program's effectiveness. Future programs should strive to develop more detailed and pre-validated survey instruments.

Additionally, the ultimate goal of nutrition education programs is to improve the dietary intake of its participants, such as by increasing consumption of vegetables and fruit. Past research has shown that nutrition education and cooking programs for children can successfully achieve these goals. Brown and Hermann (2005) reported that a short series of educational cooking 
classes led to significant increases in fruit and vegetable consumption for both children and adults who received the classes. The gains were greatest for children, who nearly doubled both their fruit and vegetable consumption from before to after the classes. Unfortunately, our study lacked any direct measurement of dietary outcomes. Future cooking and nutrition education after-school programs should aim to measure dietary intake directly through food frequency questionnaires or other recall methods to see whether the program had an effect on these key outcomes.

Further research and evaluation are needed to allow for generalizability of results. However, this study does demonstrate that after-school cooking programs created through local partnerships between after-school providers and Cooperative Extension are not only feasible, but are a promising strategy for offering hands on nutrition education to inner-city youth. Nutrition educators should aim to utilize existing after-school infrastructures to reach children in need of their services.

\section{References}

Beilin, L., \& Huang, R. (2008). Childhood obesity, hypertension, the metabolic syndrome and adult cardiovascular disease. Clinical and Experimental Pharmacology and Physiology, 35(4), 409-411.

Betts, J.R., \& Tang, Y.E. (2011). The effect of charter schools on student achievement: A metaanalysis of the literature. National Charter School Research Project Report. Available at: http://files.eric.ed.gov/fulltext/ED526353.pdf

Binkley, J. (2008). Calorie and gram differences between meals at fast food and table service restaurants. Review of Agricultural Economics, 30(4), 750-763.

Brandt, B., \& Murray, C. (2013). Take an Adventure Bite. Journal of Youth Development, 8(2), 97-105.

Brown, B.J., \& Hermann, J.R. (2005). Cooking classes increase fruit and vegetable intake and food safety behaviors in youth and adults. Journal of Nutrition Education and Behavior, 37(2), 104-105.

Cates, S., Blitstein, J., Hersey, J., Kosa, K., Flicker, L., Morgan. K. \& Bell, L. (2014). Addressing the challenges of conducting effective supplemental nutrition assistance program education (SNAP-Ed) evaluations: A step-by-step guide. Prepared by Altarum Institute and RTI International for the U.S. Department of Agriculture, Food and Nutrition Service, March 2014.

Centers for Disease Control and Prevention. (2014, March 28). Adult obesity facts. Retrieved July 8, 2014, from http://www.cdc.gov/obesity/data/adult.html

Centers for Disease Control and Prevention. (2011). School health guidelines to promote healthy eating and physical activity. Recommendations and Reports 60(5). Available at: http://www.cdc.gov/mmwr/pdf/rr/rr6005.pdf 
Contento, I. (2007). Nutrition education: Linking theory, research and practice. Sudbury, MA: Jones and Bartlett.

Daniels, S.R. (2006). The consequences of childhood overweight and obesity. The Future of Children, 16(1): 47-67.

Drewnowshi, A., \& Specter, S.E. (2004). Poverty and obesity: The role of energy density and energy costs. American Journal of Clinical Nutrition, 79:6-16.

Duyff, R.L. (2010). Home economics to family and consumer sciences: Reinvented for today's consumer. Available at:

http://www.smdisteel.org/ /media/Files/SMDI/Containers/Container\%20-

\%20Position\%20on\%20Home\%20Economics.pdf

Flegal K.M., Carroll M.D., Ogden C.L., Curtin L.R. (2010). Prevalence and trends in obesity among U.S. adults, 1999-2008. Journal of the American Medical Association, 303:235-41.

Guo S.S., \& Chumlea, W.C. (1999). Tracking of body mass index in children in relation to overweight in adulthood. American Journal of Clinical Nutrition 70(suppl):145S-148S.

Gurley-Calvez, T., \& Higginbotham, A. (2010). Childhood obesity, academic achievement, and school expenditures. Public Finance Review, 38(5), 619-646.

Janssen, I., Craig, W.M., Boyce, W.F., Pickett, W. (2004). Associations between overweight and obesity with bullying behaviors in school-aged children. Pediatrics, 113:1187-1194.

Lukas, C.V., \& Cunningham-Sabo, L. (2011). Qualitative investigation of the Cooking with Kids program: Focus group interviews with fourth-grade students, teachers, and food educators. Journal of Nutrition Education and Behavior, 43(6), 517-524.

Ogden, C., Carroll, M., Kit, B., \& Flegal, K. (2014). Prevalence of childhood and adult obesity in the United States, 2011-2012. Journal of the American Medical Association, 311(8), 806-814.

Redding, C., Rossi, J., Rossi, S., Velicer, W., \& Prochaska, J. (2000). Health behavior models. International Electronic Journal of Health Education, 3, 180-193. Available at: http://drzaius.ics.uci.edu/meta/classes/informatics161 fall06/papers/10aRedding HealthBehaviorModels.pdf

Rutgers Center for State Health Policy. (2010). New Jersey Childhood Obesity Study. Available at http://www.rwjf.org/content/dam/farm/reports/charts/2013/rwjf69256

Smith, L.P., Ng, S., \& Popkin, B.M. (2013). Trends in U.S. home food preparation and consumption: Analysis of national nutrition surveys and time use studies from 1965-1966 to 2007-2008. Nutrition Journal, 12(1), 45.

Soliah, L.A., Walter, J.M., \& Jones, S.A. (2012). Benefits and barriers to healthful eating: What are the consequences of decreased food preparation ability? American Journal of Lifestyle Medicine, 6(2), 152-158. 
Taveras, E.M., Berkey, C.S., Rifas-Shiman, S.L., Ludwig, D.S., Rockette, H.R., Field, A.E., et al. (2005). Association of consumption of fried food away from home with body mass index and diet quality in older children and adolescents. Pediatrics, 116(4), e518-e524.

U.S. Department of Agriculture Economic Research Service. (2012, May 26). Food away from home. Retrieved from http://www.ers.usda.gov/media/306585/aer829 1 .pdf

U.S. Census Bureau. (2014). USA quickfacts. Retrieved July 8, 2014 from

http://quickfacts.census.gov/qfd/states/00000.html

U.S. Census Bureau. (2014). Trenton, New Jersey quickfacts. Retrieved January 2, 2015 from http://quickfacts.census.gov/gfd/states/34/3474000.html

United States Department of Agriculture Economic Research Service. (2013). Food away from home. Available at: http://www.ers.usda.gov/topics/food-choices-health/food-consumptiondemand/food-away-from-home.aspx\#.U81HJoBdV7Q

United States Department of Agriculture Economic Research Service. (2010). How food away from home affects children's diet quality. Available at:

http://www.ers.usda.gov/publications/err-economic-research-

report/err104.aspx\#.U8106YBdV7Q

U.S. Department of Health and Human Services. (2010). The Surgeon General's Vision for a Healthy and Fit Nation. Office of the Surgeon General: Rockville, MD. Available at http://www.surgeongeneral.gov/initiatives/healthy-fit-nation/obesityvision2010.pdf

(C) Copyright of Journal of Youth Development $\sim$ Bridging Research and Practice. Content may not be copied or emailed to multiple sites or posted to a listserv without copyright holder's express written permission. Contact Editor at: patricia.dawson@oregonstate.edu for details. However, users may print, download or email articles for individual use.

ISSN 2325-4009 (Print); ISSN 2325-4017 (Online) 